\title{
KINETICS OF ADSOPTION OF METHYLENE BLUE ONTO ACTIVATED KOLANUT POD
}

\author{
Muhammad, A.S. and Abdurrahman, M.A. \\ Department of Pure and Industrial Chemistry, Bayero University, Kano. P.M.B 3011, Kano, Nigeria. \\ *Corresponding author: asmuhammed.chm@buk.edu.ng (08186615765)
}

\begin{abstract}
$A$ batch adsorption process was carried out by optimizing, the effect of contact time (10min to $180 \mathrm{~min})$ and initial concentration $(5 \mathrm{mg} / \mathrm{l}$ to150mg/I). The adsorbent was characterized using FTIR spectra and SEM, and the result obtained showed shifting and disappearance of peaks after adsorption. The results of the adsorption kinetics, which includes the correlation coefficient 0.9771 and the agreement between the amount adsorbed experimentally $(1.472 \mathrm{mg} / \mathrm{g})$ and the calculated amount absorbed $(1.196 \mathrm{mg} / \mathrm{g})$ revealed that MB was adsorbed satisfactory according to the pseudo second-order kinetic model.
\end{abstract}

Keywords: adsorption, kinetics, activation, methylene blue, dye.

\section{INTRODUCTION}

Textile industries produce one of the largest amount of wastewater due to how it consumes a large quantity of water used industrially in several ways for different purposes. Although a good number of chemicals are produced during the textile processing such as bleaching, scouring, dyeing, finishing and so forth, but the process that yield more variety of chemicals is the dyeing and finishing processes in which a variety of chemicals is widely used. If the toxicity increases, it accumulates in nature, and may lead to a terrible conclusion in environmental balance (Mishra, 2010). Contents of Textile dyes are ionic and organic, showing a strong affinity to the aqua solution and a bit on industry water (Karthik et al., 2014). Currently, numerous processes for treatment of industrial effluents containing dyes are available, amongst which includes biodegradation (Barragan et al., 2007), chemical oxidation (Feddal et al., 2013), foam flotation (Yue et al., 2008), electrolysis (Jin et al., 2003), adsorption (Wan et al., 2011) and electro-coagulation (Sami, 2012). Most of these conventional methods are inapplicable due to the high cost and disposal problems, due to the large amount of sludge generated at the end of the process (Ghoreishi and Haghighi, 2003). Adsorption is known to be a technique that gives a promising yield, ease of operation and comparably low cost of application, this have led to its great importance in the decoloration process (Mohammed et al., 2014). Yamun and Kamaraj (2016) reported a study on Pineapple peel waste activated carbon (PPWAC) as an adsorbent for the effective removal of methylene blue dye from aqueous solution. They found that the amount of dye adsorbed per unit / weight of adsorbent $(\mathrm{mg} / \mathrm{g}$ ) was concentration dependent while the effect of adsorbent dose on percent removal of the dye increased from 86.56 to $100 \%$ as the dose of the adsorbent increased from 25 to $200 \mathrm{mg} / 50 \mathrm{ml}$ of adsorbate. The effect of $\mathrm{pH}$ shows that methylene blue adsorption increases with increase in $\mathrm{pH}$ and the uptake of dye increase from $35.27 \%$ to $100 \%$ as $\mathrm{pH}$ increased from 2 to 10 .

Yusef et al. (2017) reported the study of the removal of Congo red dye from aqueous solutions by a low-cost adsorbent activated carbon prepared from Aloe vera leaves shell. They concluded that the amount of dye removal increases with increase in the dosage and the amount of dye removed increases with increase in dye initial concentration. They also used the value of the correlation coefficient $\left(R^{2}\right)$ of the Langmuir $\left(R^{2}>0.96\right)$ model to ascertain that the adsorption process obeyed Langmuir adsorption isotherm.

In this study the kinetics and mechanism of the adsorption of Methylene blue (MB) onto Activated kolanut pod(AKP) using batch adsorption process was investigated. 
BAJOPAS Volume 12 Number 2, December, 2019 MATERIALS AND METHODS

All the chemicals used in this study were of analytical reagent (AR) grade and were used without any further purification. The chemicals used are: Methylene blue (MB) with 98\% purity, hydrochloric acid (37\% purity), sodium hydroxide ( $\geq 99 \%$ purity)

\section{Sample Collection}

Approximately 100 kolanut pods and its content was obtained from Osun state, southwest of Nigeria from a village called Ikoromoja in Atakunmosa east local government near Ilesa local government.

\section{Sample Preparation}

The kolanut pods were cracked open and the content emptied, the kolanut pod were chopped in to smaller pieces to facilitate the drying process and the debris were washed thoroughly due to high viscous liquid that it produces. The rinsing of the samples were carried out with deionized water and air dried for two weeks and was subsequently washed severally with deionized water to remove all the viscous substance and finally air dried for a week, labelled and stored for further usage. (Samuel and Oladipupo, 2014) with little modification.

Preparation of the Activated Kolanut Pod

The dried sample was completely mixed with concentrated sulphuric acid (97\% purity, 1.84 specific gravity) in the ratio $1: 1$ and kept in a Muffle furnace at $300^{\circ} \mathrm{C}$ for 3 hours for activation. The material was taken out and washed severally with deionized water till the $\mathrm{pH}$ reached 7 . It was then sieved through the mesh size of $0.5 \mathrm{~mm}$ and then stored in plastic containers labelled AKP. Activation is based on the work reported by Yamun and Kamaraj (2016) with slight modification.

\section{Adsorbate Preparation}

$1 \mathrm{~g} / \mathrm{L}$ stock solution of MB was prepared by dissolving $1 \mathrm{~g}$ of the dye in 1litre volumetric flask containing $200 \mathrm{~cm}^{3}$ distilled water and then made up to the mark. Experimental solutions of the desired concentrations were obtained by dilutions from the stock solution thereafter to produce 2, 4, 6, 8, 10, 12, 14, 16, 18 and $20 \mathrm{mg} / \mathrm{L}$ for calibration curve and $10 \mathrm{mg} / \mathrm{L}$ for adsorption studies.

\section{Characterization and Analysis}

The various functional group present on the AKP surface were determined using Fourier Transform Infrared Analysis (FTIR). The concentration of $\mathrm{MB}$ in the solution was measured by PerkinElmer UV-visible spectrophotometer at the maximum wavelength of $606 \mathrm{~nm}$. The solution $\mathrm{pH}$ was determined by $\mathrm{pH}$ meter model and the surface morphology was revealed through the use of scanning electron microscope model at 2000 magnification.

\section{Batch Adsorption Experiment}

The batch adsorption process was carried out in a $120 \mathrm{ml}$ stopped bottle containing $50 \mathrm{ml}$ of 10 $\mathrm{mg} / \mathrm{L} \mathrm{MB} .0 .2 \mathrm{~g}$ of AKP was added in the solution, the dye solution was subjected to adsorption. The solutions were agitated using an electric agitator at 200rpm for $180 \mathrm{~min}$ at ambient temperature (31.5) samples were taking out and filtered after intervals of 10, 20, $30,60,90,120,150,180 \mathrm{~min}$ after which concentrations were determined using PerkinElmer UV-spectrophotometer at an absorbance wavelength of $606 \mathrm{~nm}$. The optimized time parameter was achieved by calculating the highest percentage removal using Equation1 and highest adsorption capacity using Equation2

$\%$ removal $=\left(\frac{C_{0}-C_{1}}{C_{0}}\right) \times 100$

$q_{e}=\frac{\left(C_{0}-C_{e}\right) V}{m} \times 100$

(2)

Where $C_{0}(\mathrm{mg} / \mathrm{L})$ is the initial dye concentration, $\mathrm{C}_{e}(\mathrm{mg} / \mathrm{L})$ is the equilibrium dye concentration, $\mathrm{m}(\mathrm{g})$ is the sorbent mass, and $\mathrm{V}(\mathrm{L})$ is the volume of the dye solution.

The remaining parameters such as initial concentration at intervals of $5,10,20,30,50$, 70, 100, 120 and 150ppm, initial bioadsorbent dosage at intervals of $0.2,0.3,0.4,0.5,0.6,0.7$, 0.8 and $1 \mathrm{~g}$, initial temperature at intervals of 30 , 40,50 and $60^{\circ} \mathrm{C}$ and Initial $\mathrm{pH}$ at intervals of 1 , $2,3,5,7,9$ and $11 \mathrm{pH}$ were also optimized (Samusolomon and Martin, 2011).

\section{RESULTS AND DISCUSSION}

The results of the adsorption process obtained are discussed below.

\section{RESULTS}

FT-IR spectroscopy was used to investigate the interactions between different species and changes in chemical compositions of the adsorbents before and after adsorption of the dye. Figure 1 and 2 presents FTIR spectra of the adsorbent before and after adsorption of $\mathrm{MB}$ while Table 1 presents peaks and frequencies of IR absorption. 
BAJOPAS Volume 12 Number 2, December, 2019

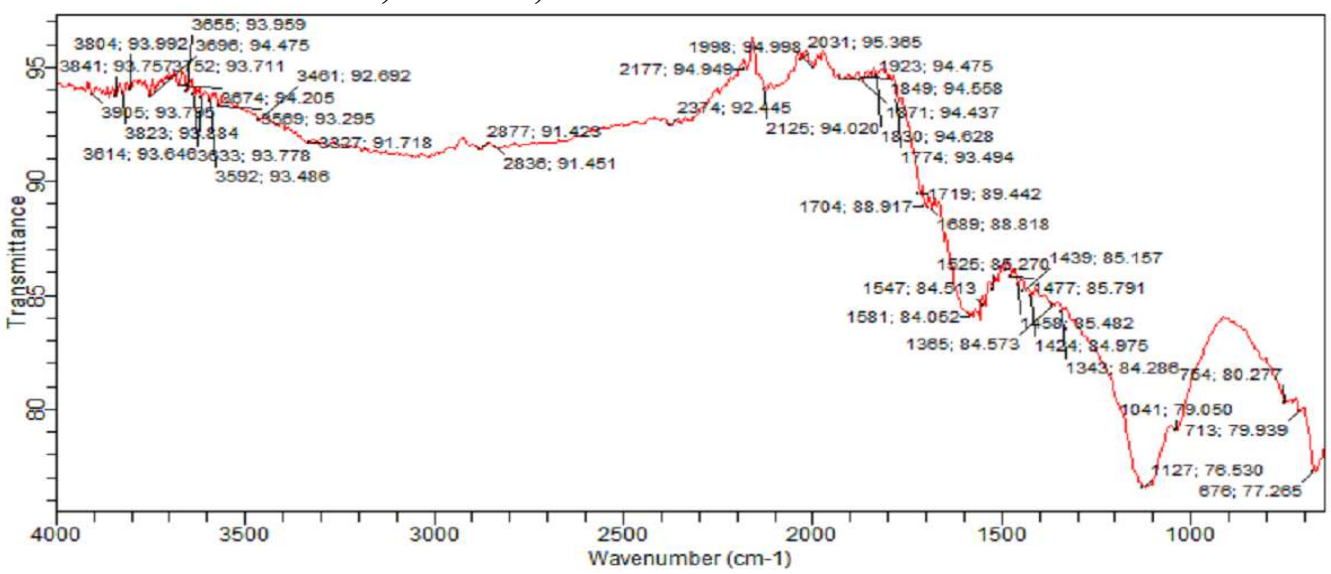

Figure 1: FTIR spectrum of AKP before adsorption

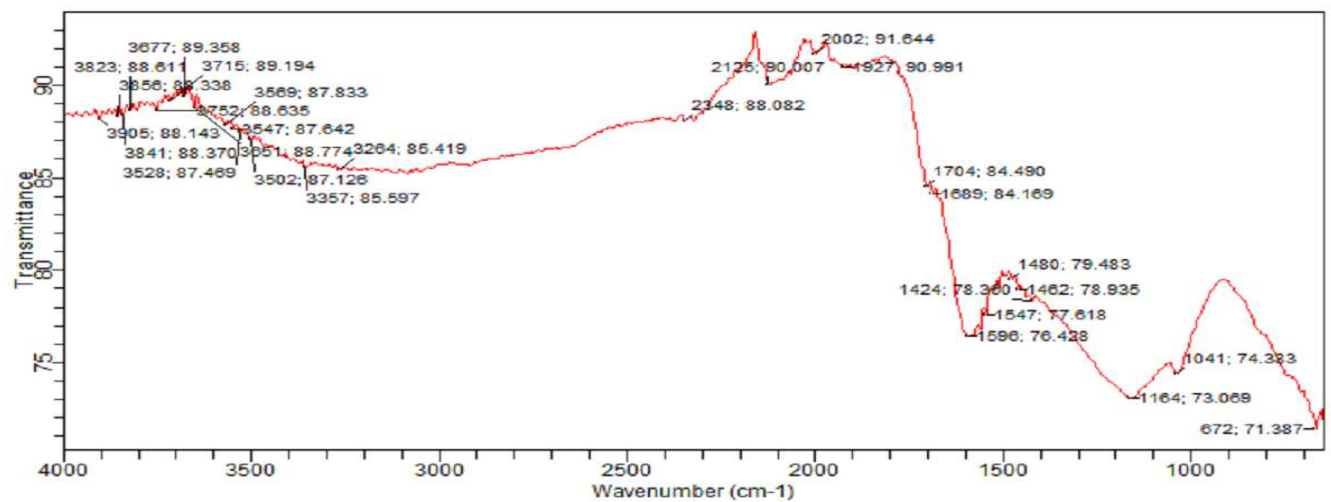

Figure 2: FTIR spectrum of AKP after adsorption of $M B$

Table 1: FTIR Spectral Data of AKP Before and After Adsorption by CR and MB

\begin{tabular}{|c|c|c|}
\hline $\begin{array}{l}\text { Before } \\
\text { Adsorption }\end{array}$ & After Adsorption & Assignment \\
\hline AKP & $\begin{array}{l}\text { AKP-MB } \\
\text { Loaded }\end{array}$ & \\
\hline 3327 & $3357(+30)$ & $\begin{array}{l}\text { O-H stretching vibration in carboxylic acid groups } \\
\left(2500-3500 \mathrm{~cm}^{-1}\right)\end{array}$ \\
\hline 2877 & - & $\begin{array}{l}\text { O-H stretching vibration in carboxylic acid groups } \\
\left(2500-3500 \mathrm{~cm}^{-1}\right)\end{array}$ \\
\hline 2836 & - & $\begin{array}{l}\text { O-H stretching vibration in carboxylic acid groups } \\
\left(2500-3500 \mathrm{~cm}^{-1}\right)\end{array}$ \\
\hline 1719 & - & $\begin{array}{l}\text { General presence of } \mathrm{C}=0 \text { groups stretching } \\
\text { vibrations }\left(1650-1800 \mathrm{~cm}^{-1}\right)\end{array}$ \\
\hline 1547 & - & $\begin{array}{l}\mathrm{NO}_{2} \text { in aliphatic nitro compounds due to } \\
\text { antisymmetric stretching }\left(1575-1545 \mathrm{~cm}^{-1}\right)\end{array}$ \\
\hline 1424 & $1402(-22)$ & $\begin{array}{l}\mathrm{OH} \text { in carboxylic acid groups due to in-plane } \mathrm{OH} \\
\text { bending }\left(1440-1400 \mathrm{~cm}^{-1}\right)\end{array}$ \\
\hline 1127 & $1164(+37)$ & C-N stretching vibration in amines $\left(1030-1330 \mathrm{~cm}^{-1}\right)$ \\
\hline 676 & $672(-4)$ & $\begin{array}{l}\mathrm{O}-\mathrm{C}=\mathrm{O} \text { in carboxylic acid groups due to } \mathrm{O}-\mathrm{C}=\mathrm{O} \\
\text { bending ( } 700-590 \mathrm{~cm}-1) ; \quad \mathrm{C}-\mathrm{C}-\mathrm{CHO} \text { in aldehyde } \\
\text { compounds due to } \mathrm{C}-\mathrm{C}-\mathrm{CHO} \text { bending }\left(695-635 \mathrm{~cm}^{-1}\right)\end{array}$ \\
\hline
\end{tabular}

Scanning Electron Microscopy studies provide useful information regarding the surface morphology of the adsorbents. The SEM images of the AKP before adsorption are presented in Figures 3 and 4. 

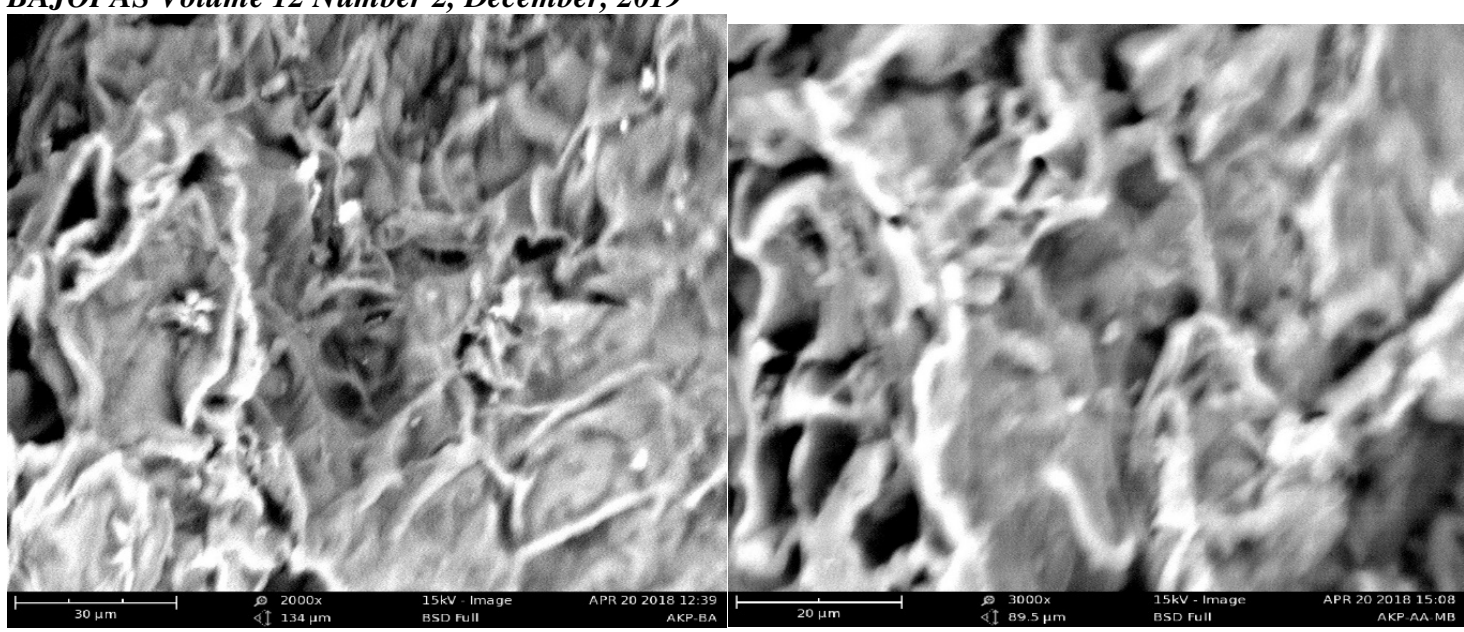

Figure 3: SEM micrograph of AKP before Adsorption

Figure 4: SEM micrograph of AKP after Adsorption of MB

\section{Effect of Contact Time}

The effect of contact time for the adsorption of MB onto AKP was studied, the result is as shown in figure 5

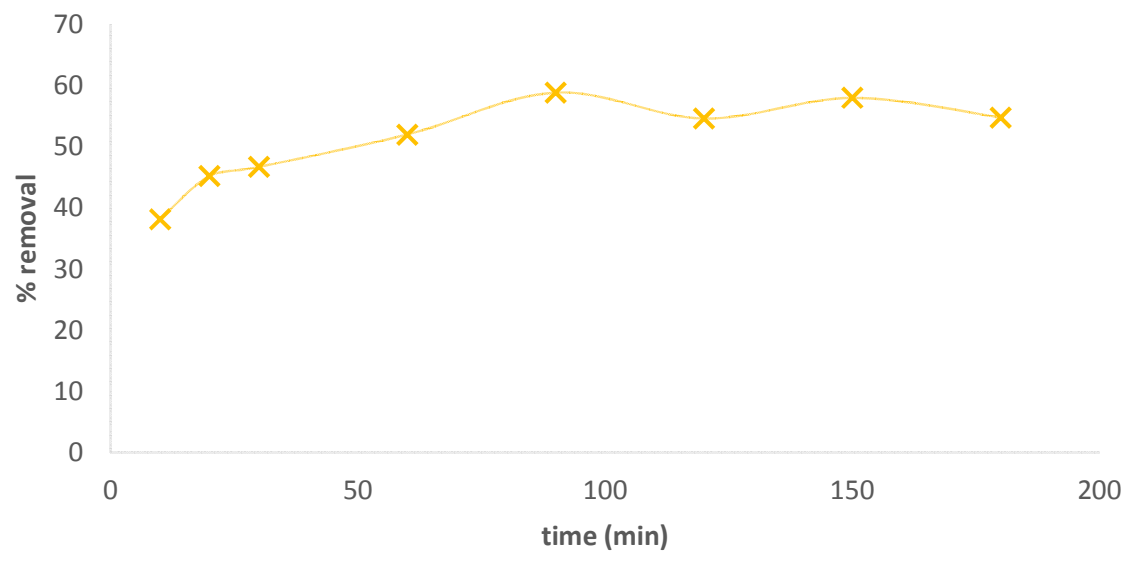

Figure 5: Effect of Contact Time on the Adsorption of MB onto the AKP

\section{Effect of Initial MB Concentration}

Figure 6 shows the effect of initial dye concentration for the adsorption MB onto AKP.

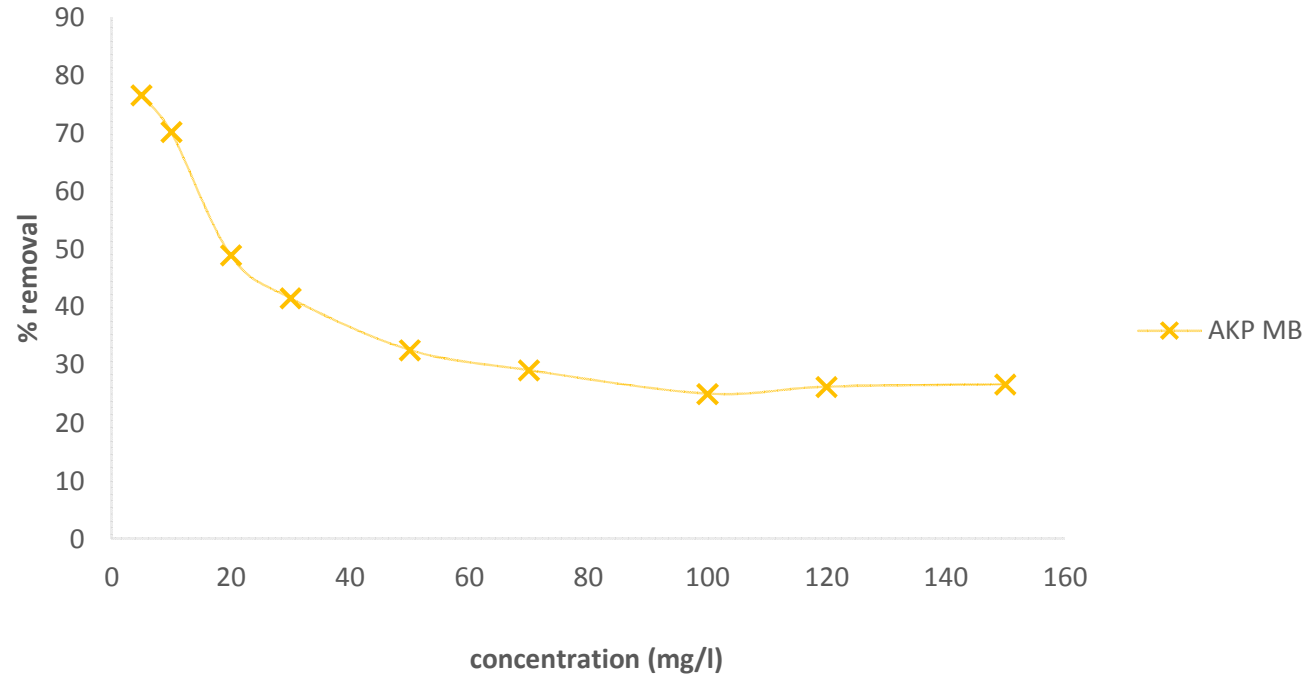

Figure 6: Effect of Initial MB Concentration 
BAJOPAS Volume 12 Number 2, December, 2019

Kinetics studies

The kinetics of the adsorption MB onto AKP was investigated using the Pseudo first-order, Pseudo second-order and Elovich models and the results are shown in Table 2.

Table 2: Kinetic Parameters for the removal of MB from Aqueous Solution onto AKP.

Model Kinetic parameter

\begin{tabular}{lll}
\hline & $\mathrm{q}_{\mathrm{e}, \text { exp. }}(\mathrm{mg} / \mathrm{g})$ & 1.472 \\
PFO & $\mathrm{q}_{\mathrm{e}, \text { cal. }}(\mathrm{mg} / \mathrm{g})$ & 0.291 \\
& $\mathrm{k}_{1}\left(\mathrm{~min}^{-1}\right)$ & 0.0022 \\
PSO & $\mathrm{R}^{2}$ & 0.0472 \\
& $\mathrm{q}_{\mathrm{e}, \text { cal. }}(\mathrm{mg} / \mathrm{g})$ & 1.196 \\
& $\mathrm{k}_{2}(\mathrm{~g} / \mathrm{mg} \cdot \mathrm{min})$ & -8.491 \\
Elovich & $\mathrm{R}^{2}$ & 0.9862 \\
& $\mathrm{a}(\mathrm{mg} / \mathrm{g} \cdot \mathrm{min})$ & $7.32 \times 10^{3}$ \\
& $\beta(\mathrm{mg} / \mathrm{g})$ & 12.610 \\
& $\mathrm{R}^{2}$ & 0.3254 \\
\hline $\mathrm{C}_{0}=10 \mathrm{mg} / \mathrm{L}, \mathrm{m}=0.2 \mathrm{~g}, \mathrm{~T}=304.5 \mathrm{~K}$. &
\end{tabular}

\section{DISCUSSION}

Scanning Electron Microscopy studies provide useful information regarding the surface morphology of the adsorbents. Generally the adsorbent with porous and rough morphology has high adsorption capacity (Olajire et al., 2017). It can be seen in figure 3 that the micrograph of AKP before adsorption is porous in nature with grain boundaries, while the micrograph in figure 4 after adsorption shows reduction in the amount of pores present before adsorption, which is an evidence that adsorption have truly taking place.

Figure 5 shows the percentage removal rapidly increases at the first $10 \mathrm{~min}$ and then slowly to obtain the equilibrium which was achieved at $90 \mathrm{~min}$. In general, the rate of dye removal increases with an increase in contact time to a certain extent (Rosmawani, 2017). The result revealed that the rate of dye removal gradually increases with an increase in time until it attained equilibrium. Due to deposition of dyes on the available adsorption site on adsorbent, any additional increase in contact time will not increase the uptake (Bharathi and Ramesh, 2013).

The effect of initial dye concentration of the above experiments were plotted in Fig.6. The percentage of MB removal increases with increasing the initial concentration from 5 to $20 \mathrm{mg} / \mathrm{l}$. This is because the active sites on the adsorbent surface are not fully occupied and the AKP will adsorb the dye until it reaches its maximum adsorption capacity (Kannan and Sundaram, 2001). However, the percentage of removal decreases after $20 \mathrm{mg} / \mathrm{L}$ of initial MB concentration, this is due to the adsorption capacity limitation of the adsorbent (Salleh et al., 2011).

To model the adsorption kinetics of MB onto AKP, three simple kinetic models were tested as shown in Table II. The adsorption data was analyzed in terms of pseudo-first-order (PFO), pseudo second-order (PSO) mechanisms and Elovich model using equation 3,4 and 5 respectively. The slope of the three graphs either pseudo first-order mechanism pseudo second-order mechanism or Elovich model that gave a linear relationship or having the highest correlation coefficient indicates which kinetics are applicable to the adsorption of CR and MB on relative adsorbents.

$\ln \left(\mathrm{q}_{\mathrm{e}}-\mathrm{q}_{\mathrm{t}}\right)=\ln \mathrm{q}_{\mathrm{e}}-\mathrm{k}_{1} \mathrm{t}$ whereq amount of adsorbent adsorbed at equilibrium $(\mathrm{mg} / \mathrm{g}), \mathrm{q}_{\mathrm{t}}$ amount of adsorbent adsorbed at equilibrium at a specific time interval $(\mathrm{mg} / \mathrm{g}), \mathrm{k}_{1}$ Lagergren rate constant $(1 / \mathrm{h})$, t Contact time (h).

Plottingln $\left(q_{e}-q_{t}\right)$ vs.t gives a straight line that passes through the origin with a slope $k_{1}$ for systems that obey this model.

The PSO model assumes that the uptake rate is second order with respect to the available surface sites (Ho and McKay, 2000).

$\frac{t}{q}=\frac{1}{k_{2} q_{\mathrm{e}}^{2}}+\frac{\mathrm{t}}{q_{e}}$

Where $k_{2}$ is the pseudo-second-order (PSO) rate constant. Other Symbols have the same meanings as in the PFO model.

A plot of $\frac{t}{q}$ vs $t$ gives a straight line for PSOcompliant kinetics. The slope is $\frac{1}{q_{e}}$, and the intercept is $\frac{1}{k_{2} q_{\mathrm{e}}^{2}}$ (Ho and McKay, 2000)

The Elovich equation is expressed as

$q=\frac{1}{\beta} \ln (\alpha \beta)+\frac{1}{\beta} \ln t$ 
BAJOPAS Volume 12 Number 2, December, 2019 Kinetics that obeys Elovich equation should produce a straight line on the plot of $q$ vs $\ln t$. The slope is $1 / \beta$, and the intercept is $(\operatorname{In}(a \beta)) / \beta$. $\alpha$ is the initial adsorption rate $(\mathrm{mg} / \mathrm{g} \cdot \min )$, and $\beta$ is a desorption constant related to the extent of surface coverage and activation energy for chemisorption.

The adsorption parameters derived from the application of the pseudo-first-order equation ( $K_{1}$ and $\left.\mathrm{q}_{\mathrm{e}}\right)$, the pseudo-second-order equation $\left(\mathrm{K}_{2}\right.$, $\mathrm{q}_{\mathrm{e}}$ ) and Elovich's equation were calculated and are listed in Table 2 . The low correlation coefficients, $\mathrm{R}^{2}$, of the PFO and Elovich suggest that both models are not applicable to fit the experimental data. In addition, there is no agreement between the $\mathrm{q}_{\mathrm{e}}$, experimental and $\mathrm{q}_{\mathrm{e}}$ calculated values for the PFO model. The correlation coefficients of the pseudo-secondorder model of AKP for the adsorption of $M B$ is

\section{REFERENCES}

Barragan, B.E., Costa C., Carmen Marquez M. (2007). Biodegradation of azo dyes by bacteria inoculated on solid media, Dye. Pigment. 75:73-81.

Bharathi, K.S. and Ramesh, S.T. (2013). Removal of dyes using agricultural waste as low-cost adsorbents: a review, Appl. Water Sci. 3:773-790.

Feddal, I. Ramadani, A. Taleb, S. Gaigneaux, Batis, Ghaffour ((2013). Adsorption capacity of methylene blue, an organic pollutant, by montmorillonite clay. Desalin. Water Treat, 52:2654-2661.

Ghoreishi, S.M. and Haghighi R. (2003). Chemical catalytic reaction and biological oxidation for treatment of non-biodegradable textile effluent, Chem. Eng. J., 95, 163-169.

Ho, Y.S., McKay G. (2000). The kinetics of sorption of divalent metal ions onto sphagnum moss peat. Water Res, 34:735-742.

Jin, Y.Z., Zhang Y.F. and W.L., (2003). Micro-electrolysis technology for industrial wastewater treatment. Bioresour. Technol., 15, 334-338.

Kannan, N. and Sundaram, M. M. (2001).Kinetics and mechanism of removal of methylene blue by adsorption on various carbons - a comparative study. Dyes and Pigments. 51: 25-40.

Karthik, V, Saravanan K, Bharathi P, Dharanya V, Meiaraj C (2014). An overview of treatments for the removal of textile dyes. Journal of Chemical and Pharmaceutical Sciences 7: 301-307.
0.9862 , which indicates the suitability of the pseudo second-order equation for adsorption process. In addition, the percentage removal values of AKP in the adsorption of $M B$ is $54.30 \%$, which is close to that of the experimental data. These results show that the adsorption of MB from aqueous solution onto AKP obeys the PSO kinetic model and could be used to determine the equilibrium adsorption capacity and rate constant.

\section{CONCLUSION}

The study shows that AKP is an important agricultural by product for the removal of $M B$ from aqueous solution. The kinetics data obtained was found to be best fitted to pseudo second-order. This is due to the agreement the calculated and experimental amount adsorbed.

Mishra, AK, Arockiadoss T, Ramaprabhu S (2010). Study of removal of azo dye by functionalized multi walled carbon nanotubes. Chemical Engineering Journal 162:1026-1034.

Mohammed, M.A., Shitu A. and Ibrahim A., (2014). Removal of Methylene Blue Using Low Cost Adsorbent, research journal of chemical science. 4(1): 91102.

Olajire, A.A. Abidemi J.J. Lateef A. and Benson N. U. (2017). Adsorptive Desulphurization of Model Oil by $\mathrm{Ag}$ Nanoparticle-Modified Activated Carbon Prepared from Brewer's Spent Grains. Journal of Environmental Chemical Engineering. 5:147-159.

Rosmawani Mohammad, Aswinee Tangga Rajoo and Mardawani Mohamad (2017). Coconut Fronds As Adsorbent In The Removal of Malachite Green Dye. ARPN Journal of Engineering and Applied Sciences. 12(4).

Saeedi, Hassan Basiri (2017). Removal of Congo red dye from aqueous solutions by a low-cost adsorbent: activated carbon prepared from Aloe vera leaves shell. Environmental Health Engineering and Management Journal, 4(1), 29-35.

Salleh, M. A. M., Mahmoud D. K., Karim W. A. W. A. and Idris A. (2011). Cationic and anionic dye adsorption by agricultural solid wastes: a comprehensive review. Desali. 280: 1-13.

Sami, G., (2012). Sorption Kinetics for Dye Removal From Aqueous Solution Using Natural Clay, J. Environ. Earth Sci. ISSN2, 30-40. 
BAJOPAS Volume 12 Number 2, December, 2019

Samuel Agarry, Oladipupo Ogunleye (2014). Chemically treated kola nut pod as low-cost natural adsorbent for the removal of 2, 4 dinitrophenol from synthetic wastewater: batch equilibrium, kinetic, and thermodynamic modelling studies. Turkish Journal of Engineering and Environmental Sciences.

Samusolomon J. and Martin Devaprasath P. (2011). Removal of alizarin red s (dye) from aqueous media by using cynodondactylodomas an adsorbent. Journal of chemical and pharmaceutical research, 3(5):478490.

Wan Ngah, W.S., Teong L.C. and Hanafiah M.A.K.M. (2011). Adsorption of dyes and heavy metal ions by chitosan composites: $A$ review, Carbohydr. Polym. 83:1446-1456.
Yamun, M. and Kamaraj, M. (2016). Pineapple peel waste activated carbon as an adsorbent for the effective removal of methylene blue dye from aqueous solution. International Journal of Chem. Tech Research, 9(5):544-550.

Yue, Q. Y., Gao, B.Y., Wang, Y., Zhang, H., Sun, X., Wang S. G., and. Gu R. R. (2008). Synthesis of polyamine flocculants and their potential use in treating dye waste water, J. Hazard. Mater. 152:221-227.

Yusef, Omidi Khaniabadi, Mohammad Javad Mohammadi, Mojtaba Shegerd, Shahram Sadeghi, Sedigheh Saeedi, Hassan Basiri (2017). Removal of Congo red dye from aqueous solutions by a low-cost adsorbent: activated carbon prepared from Aloe vera leaves shell. Environmental Health Engineering and Management Journal, 4(1), 29-35 